\title{
Article \\ Optimal Price and Lot Size for an EOQ Model with Full Backordering under Power Price and Time Dependent Demand
}

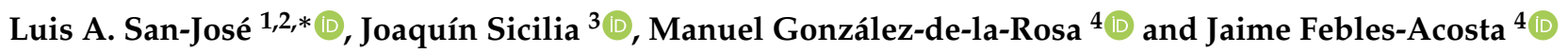 \\ 1 IMUVA-Mathematics Research Institute, University of Valladolid, 47011 Valladolid, Spain \\ 2 Department of Applied Mathematics, University of Valladolid, 47011 Valladolid, Spain \\ 3 Department of Mathematics, Statistics and Operational Research, University of La Laguna, \\ 38200 San Cristóbal de La Laguna, Spain; jsicilia@ull.es \\ 4 Department of Business Administration and Economic History, University of La Laguna, \\ 38200 San Cristóbal de La Laguna, Spain; mgonzale@ull.es (M.G.-d.-1.-R.); jfebles@ull.es (J.F.-A.) \\ * Correspondence: augusto@mat.uva.es
}

Citation: San-José, L.A.; Sicilia, J.; González-de-la-Rosa, M.

Febles-Acosta, J. Optimal Price and Lot Size for an EOQ Model with Full Backordering under Power Price and Time Dependent Demand. Mathematics 2021, 9, 1848. https:// doi.org/10.3390/math9161848

Academic Editor: Bahram Adrangi

Received: 18 June 2021

Accepted: 2 August 2021

Published: 5 August 2021

Publisher's Note: MDPI stays neutral with regard to jurisdictional claims in published maps and institutional affiliations.

Copyright: (c) 2021 by the authors. Licensee MDPI, Basel, Switzerland. This article is an open access article distributed under the terms and conditions of the Creative Commons Attribution (CC BY) license (https:// creativecommons.org/licenses/by/ $4.0 /)$.

\begin{abstract}
In this paper, we address an inventory system where the demand rate multiplicatively combines the effects of time and selling price. It is assumed that the demand rate is the product of two power functions, one depending on the selling price and the other on the time elapsed since the last inventory replenishment. Shortages are allowed and fully backlogged. The aim is to obtain the lot sizing, the inventory cycle and the unit selling price that maximize the profit per unit time. To achieve this, two efficient algorithms are proposed to obtain the optimal solution to the inventory problem for all possible parameter values of the system. We solve several numerical examples to illustrate the theoretical results and the solution methodology. We also develop a numerical sensitivity analysis of the optimal inventory policy and the maximum profit with respect to the parameters of the demand function.
\end{abstract}

Keywords: EOQ inventory model; shortages; lot sizing; optimal pricing; profit maximization

\section{Introduction}

Inventory Theory collects a set of mathematical models which describe the properties of a wide variety of inventory systems, and studies different methodologies to seek and analyze the best strategies that may be applied in the management of inventories. In the literature on inventory models, the demand rate of items is often assumed to be constant and known, independent of the time elapsed since the last replenishment. Thus, Chung et al. [1] provide the optimal solution for an inventory model with lot-size-dependent trade credit under delayed payment, cash discount and constant demand rate. Vandana and Sharma [2] developed an inventory model with constant demand, partial backlogging and partial permissible delay-in-payment. Mokhtari [3] proposed an economic order quantity model with constant demand to determine the joint ordering policy for two products under completion and substitution. Other recent papers considering constant demand are the following: Lin et al. [4], Chung et al. [5], Khakzad and Gholamian [6] and Mishra et al. [7].

However, for some types of products, the demand rate often depends on time or/and other characteristics. For this reason, in this paper, we develop an inventory model to determine the optimal policy for products in which demand depends on time and the selling price of the item. Thus, the demand rate is the product of a power time-function and a decreasing price-function. This price-function is a power-function that depends on several parameters and represents the relation between demand and the unit selling price. The power timedependent demand pattern was introduced by Naddor [8] and, since then, several papers have appeared in the literature with this type of demand. Among others, we can cite the papers of Datta and Pal [9], Lee and Wu [10], Rajeswari and Vanjikkodi [11], Mishra et al. [12], Singh and Kumar [13], Mishra and Singh [14] and Rajeswari and Indrani [15]. A common 
characteristic of all the above papers is that the length of the inventory cycle is fixed. Later on, Sicilia et al. [16,17], San-José et al. [18], Adaraniwon and Omar [19,20] and SanJosé et al. [21] developed inventory systems with a power demand pattern in which the inventory cycle is not fixed and is, therefore, a decision variable of the inventory problem. Demand rate as a separable function of time and the selling price was also introduced in some articles on inventory management. Thus, the papers developed by Smith et al. [22], Soni [23], Wu et al. [24], Avinadav et al. [25], San-José et al. [26] and Pando et al. [27] considered this assumption.

In some real inventory systems, it may be more advantageous for the firm that the customers have to wait a time period until the arrival of the next replenishment to receive their orders. Thus, in this paper, we assume that shortages are allowed and completely backordered. That is, any customer arriving in the stock-out period is willing to wait for the next replenishment. This hypothesis of full backordering is also considered in other papers (see, e.g., San-José and García-Laguna [28], Birbil et al. [29], Jakic and Fransoo [30], Mishra et al. [31] and San-José et al. [32]).

In the inventory literature, we know of no papers on inventory systems that simultaneously assume the following characteristics: demand rate is the product of a time-dependent power demand and a price-dependent power demand, shortages are completely backordered and the length of the inventory cycle is a decision variable. The inventory system studied here is based on these assumptions. The objective function to optimize is the profit per unit time. This profit is calculated by the difference between the revenue from product sales and the sum of ordering cost, purchasing cost, holding cost and backordering cost. The aim is to determine the optimal inventory policy (the economic lot size and optimal inventory cycle) and the optimal selling price that maximize the total profit per unit time. Under the above considerations, a new approach is developed for determining the optimal policy and the best selling-price of the product, taking into account the values of the parameters considered in the inventory system.

The outline of the paper is described below. Section 2 specifies the hypothesis of the model and the notation used in the rest of the work. Section 3 presents the mathematical formulation, including the calculation of costs related to the management of the inventory system and the establishment of the profit function per unit of time. Section 4 studies some properties of the objective function and develops algorithmic procedures that allow to determine the optimal inventory policy for the two different situations that can occur. In Section 5, we introduce some numerical examples to illustrate the application of the optimization procedures. Moreover, we also give a numerical sensitivity analysis for the best selling price, the optimal inventory policy and maximum profit with respect to the parameters of the demand rate function. Finally, in Section 6, we provide the conclusions of this paper and possible future research directions in this area.

\section{Hypothesis and Notation}

The inventory system analyzed in this work has the following properties:

1. The inventory system considers a single item.

2. Inventory control is performed through a continuous review system.

3. The replenishment period is negligible or null.

4. The planning horizon is infinite.

5. The lead-time is zero.

6. The inventory is scheduled each $T$ time unit. It is a decision variable.

7. The cost of placing an order is constant and independent of the size of the order.

8. The unit purchasing cost is known and constant.

9. The unit selling price is unknown and it is a decision variable.

10. The unit holding cost is a linear function of the time that the article remains in the store.

11. Shortages are allowed and completely backlogged.

12. The unit cost of shortage is a linear function of the time that elapses until the item is received. 
13. The inventory is replenished when the number of backorders is equal to $-s$ quantity units. That is, the reorder level is $s$.

14. The replenishment size $Q$ raises the inventory at the beginning of each scheduling period to the order level $S$.

15. Demand $D(t, p)$ is a function that depends on time and the selling price of the item. It is assumed that

$$
D(t, p)=D_{1}(t) D_{2}(p),
$$

that is, demand combines the effects of time and the selling price in a multiplicative way.

In this paper, it is assumed that $D_{1}(t)$ is a power function given by

$$
D_{1}(t)=\frac{1}{n}\left(\frac{t}{T}\right)^{1 / n-1}, 0<t<T
$$

with index $n>0$, and $D_{2}(p)$ is a decreasing power function given by

$$
D_{2}(p)=\alpha-\beta p^{\gamma}, \text { with } \alpha>0, \beta>0 \text { and } \gamma>0 \text {. }
$$

The parameter $\alpha$ represents the market size and the parameters $\beta$ and $\gamma$ are the coefficients related to the sensibility of demand with respect to the unit selling price. As $D(t, p) \geq 0$, then the maximum unit selling price is

$$
p_{m}=\left(\frac{\alpha}{\beta}\right)^{1 / \gamma}
$$

Note that the demand patterns represent the different ways by which quantities are taken out of inventory to fill customer demand. Given $p$, the function $D(t, p)$ is known as the power demand pattern. Depending on the value of the index $n$, that function $D(t, p)$ may represent several ways in which demand occurs during an inventory cycle (see, e.g., Naddor [8], Mishra et al. [12], Singh and Kumar [13], Rajeswari and Indrani [15], Sicilia et al. [16,17], and San-José et al. [18,21,32]). Thus, if $n>1$, then this means that demand is large at the beginning of the scheduling period and then declines throughout the inventory cycle. If $n=1$, the demand is constant throughout the scheduling period. Finally, if $n<1$, then demand is very low at the beginning of the scheduling period and then increases throughout the inventory cycle, reaching the highest demand at the end of the cycle.

Figures 1-3 plot the demand rate function $D(t, p)$ for different values of the parameters $\gamma$ and $n$.

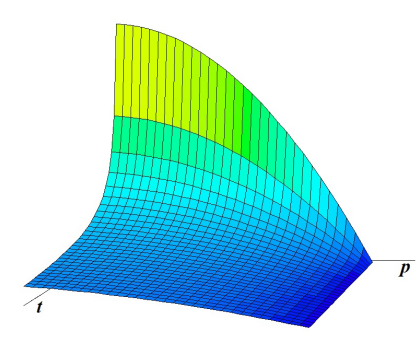

$\gamma>1$

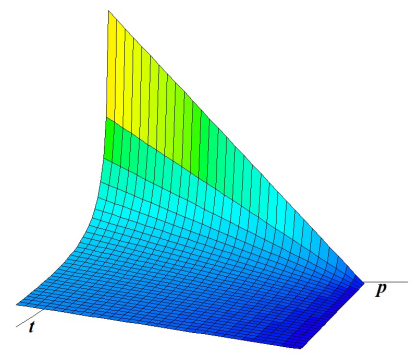

$\gamma=1$

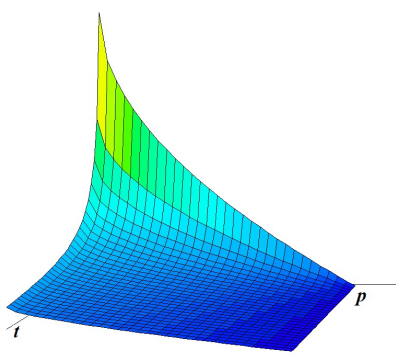

$\gamma<1$

Figure 1. Demand functions $D(t, p)$ when $n>1$. 


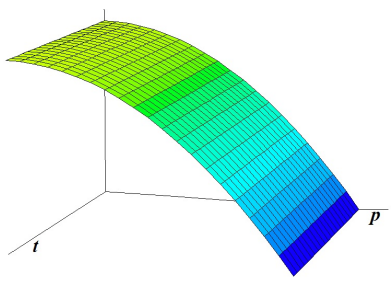

$\gamma>1$

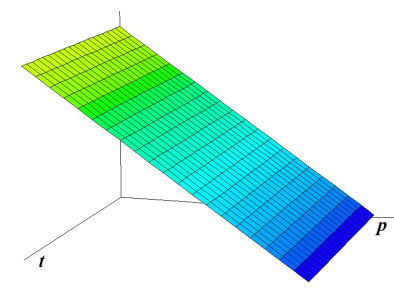

$\gamma=1$

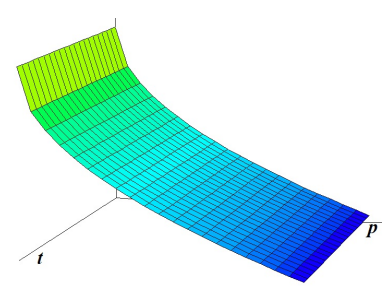

$\gamma<1$

Figure 2. Demand functions $D(t, p)$ when $n=1$.

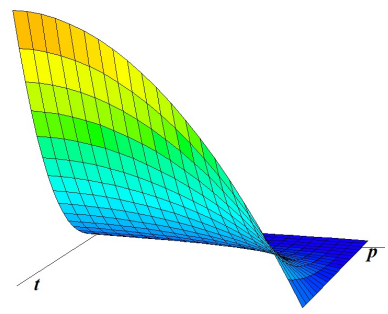

$\gamma>1$

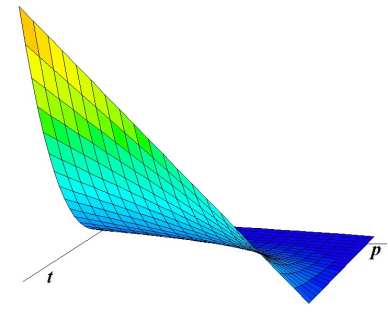

$\gamma=1$

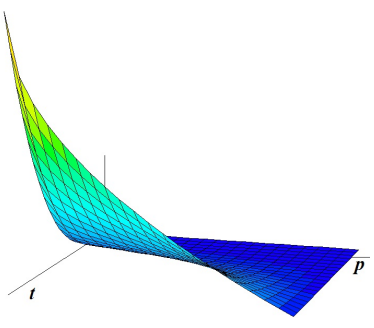

$\gamma<1$

Figure 3. Demand functions $D(t, p)$ when $n<1$.

The notation used throughout this work is shown in Table 1.

Table 1. Notation.

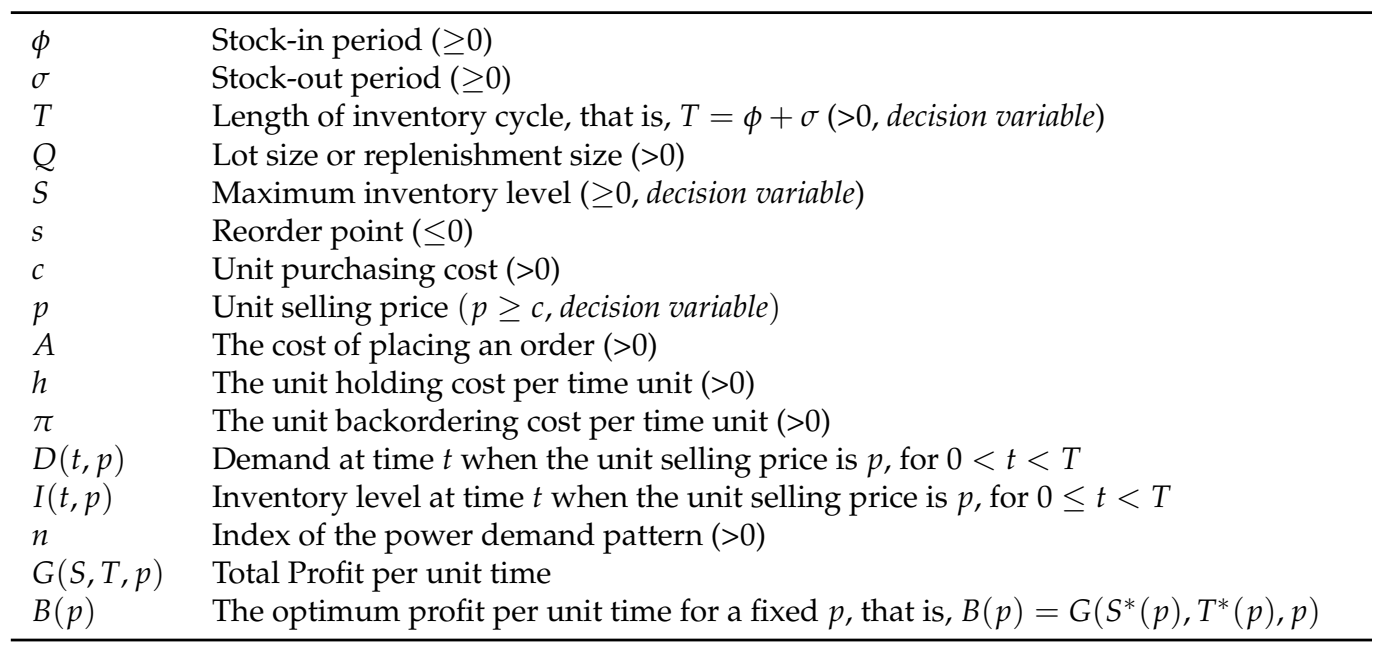

In the next section, we determine the inventory level function $I(t, p)$, which describes the evolution of the net inventory, and the costs related to the inventory system.

\section{Formulation of the Mathematical Model}

The fluctuation of the inventory level during the inventory cycle $T$ is as follows: At the beginning of the scheduling period, there are $S$ units in stock. That amount decreases due to demand during the interval $(0, \phi]$ and drops to zero at $t=\phi$. Thus, we have

$$
S=\int_{0}^{\phi} D(t, p) d t
$$

Next, during the interval $[\phi, T]$, the inventory level decreases continuously due to the effect of customer demand. During this period there is no stock, shortages occur and demand is backlogged. When the on-hand inventory level is equal to $s$ (reorder point), a 
new replenishment is added to the inventory and a new inventory cycle begins. Hence, the inventory level at any instant of time $t$ during $[0, T]$ is described by

$$
I(t, p)=S-\int_{0}^{t} D(t, p) d t=D_{2}(p) \int_{t}^{\phi} D_{1}(t) d t .
$$

From (1) and (2), substituting the functions $D_{1}(t)$ and $D_{2}(p)$ into (5), we have

$$
I(t, p)=\left(\alpha-\beta p^{\gamma}\right) T\left[\left(\frac{\phi}{T}\right)^{1 / n}-\left(\frac{t}{T}\right)^{1 / n}\right]=S-\left(\alpha-\beta p^{\gamma}\right) T\left(\frac{t}{T}\right)^{1 / n} .
$$

As at point $t=0$ the inventory level is equal to $S$, then we have

$$
S=\left(\alpha-\beta p^{\gamma}\right) T\left(\frac{\phi}{T}\right)^{1 / n}
$$

Also, at the point $t=T$, the inventory level coincides to the reorder point, that is, $s=I(T, p)$. Hence, we obtain

$$
s=I(T, p)=\left(\alpha-\beta p^{\gamma}\right) T\left[\left(\frac{\phi}{T}\right)^{1 / n}-1\right] .
$$

The lot size $Q$ is equal to $S-s$. Thus, from (7) and (8), we have

$$
Q=\left(\alpha-\beta p^{\gamma}\right) T
$$

The Objective Function

Let $G(S, T, p)$ be the profit per unit time. That profit is equal to the revenues per cycle $(p Q)$ minus the sum of the costs related to the inventory management. These costs are the purchasing $\operatorname{cost}(c Q)$, the ordering $\operatorname{cost}(A)$, the holding cost $(H C)$ and the shortage cost (SC). The holding cost is given by

$$
H C=h \int_{0}^{\phi} I(t, p) d t=\frac{h}{n+1} S T\left(\frac{S}{\left(\alpha-\beta p^{\gamma}\right) T}\right)^{n}
$$

and the shortage cost is

$$
S C=\pi \int_{\phi}^{T}[-I(t, p)] d t=\pi\left[\frac{n}{n+1}\left(\alpha-\beta p^{\gamma}\right) T^{2}-S T+\frac{1}{n+1} S T\left(\frac{S}{\left(\alpha-\beta p^{\gamma}\right) T}\right)^{n}\right] .
$$

Hence, the profit per time unit is given by

$$
\begin{aligned}
G(S, T, p)= & \frac{1}{T}\left[(p-c) Q-A-h \int_{0}^{\phi} I(t, p) d t+\pi \int_{\phi}^{T} I(t, p) d t\right] \\
= & (p-c)\left(\alpha-\beta p^{\gamma}\right)-\frac{A}{T}-\frac{h+\pi}{n+1} S\left(\frac{S}{\left(\alpha-\beta p^{\gamma}\right) T}\right)^{n} \\
& \quad-\frac{n}{n+1} \pi\left(\alpha-\beta p^{\gamma}\right) T+\pi S
\end{aligned}
$$

Our goal is to determine the values of the decision variables $S, T$ and $p$ that maximize the profit $G(S, T, p)$ per unit time, subject to the constraints $T>0,0 \leq S \leq\left(\alpha-\beta p^{\gamma}\right) T$ and $c \leq p \leq p_{m}$, with $p_{m}$ given by (3). 


\section{Analysis of the Inventory Problem}

It is easy to check that, for a fixed $p$, the function $G(S, T, p)$ is strictly concave and has a maximum point $\left(S^{*}(p), T^{*}(p)\right)$ determined by

$$
\begin{aligned}
& S^{*}(p)=\left(\frac{\pi}{h+\pi}\right)^{1 / n}\left(\alpha-\beta p^{\gamma}\right) \sqrt{\frac{(n+1) A}{n\left(\alpha-\beta p^{\gamma}\right) \pi\left(1-\left(\frac{\pi}{h+\pi}\right)^{1 / n}\right)}} \\
& T^{*}(p)=\sqrt{\frac{(n+1) A}{n\left(\alpha-\beta p^{\gamma}\right) \pi\left(1-\left(\frac{\pi}{h+\pi}\right)^{1 / n}\right)}}
\end{aligned}
$$

Thus, given $p$, the optimum profit per unit time is

$$
B(p)=G\left(S^{*}(p), T^{*}(p), p\right)=(p-c)\left(\alpha-\beta p^{\gamma}\right)-2 \sqrt{\alpha-\beta p^{\gamma}} \theta,
$$

where the auxiliary parameter $\theta$ is given by

$$
\theta=\sqrt{\frac{n}{n+1} A \pi\left(1-\left(\frac{\pi}{h+\pi}\right)^{1 / n}\right)} .
$$

The function $B(p)$ has the following properties:

(i) $B(p)$ is continuous on the interval $\left[c, p_{m}\right]$. Moreover, $B(c)<0$ and $B\left(p_{m}\right)=0$.

(ii) $B(p)$ is differentiable and its derivative is

$$
\begin{aligned}
B^{\prime}(p) & =\alpha+\beta p^{\gamma-1}\left(\gamma c+\frac{\gamma \theta}{\sqrt{\alpha-\beta p^{\gamma}}}-(\gamma+1) p\right) \\
& =\beta p^{\gamma-1}\left(\frac{\alpha}{\beta} p^{1-\gamma}+\gamma c+\frac{\gamma \theta}{\sqrt{\alpha-\beta p^{\gamma}}}-(\gamma+1) p\right)
\end{aligned}
$$

(iii) $\operatorname{Sign}\left(B^{\prime}(p)\right)=\operatorname{sign}(f(p))$, where the function $f(p)$ is defined by

$$
f(p)=\gamma c-(\gamma+1) p+\frac{\alpha}{\beta} p^{1-\gamma}+\frac{\gamma \theta}{\sqrt{\alpha-\beta p^{\gamma}}} .
$$

Thus, the maximum of the function $B(p)$ can be found by analyzing the function $f(p)$. For that, we calculate the two first derivatives of the function $f(p)$ :

$$
f^{\prime}(p)=-(\gamma+1)+\frac{\alpha}{\beta}(1-\gamma) p^{-\gamma}+\frac{\beta \gamma^{2} \theta p^{\gamma-1}}{2 \sqrt{\left(\alpha-\beta p^{\gamma}\right)^{3}}}
$$

and

$$
f^{\prime \prime}(p)=(\gamma-1)\left(\frac{\alpha \gamma}{\beta} p^{-(\gamma+1)}+\frac{\alpha \beta \gamma^{2} \theta p^{\gamma-2}}{2 \sqrt{\left(\alpha-\beta p^{\gamma}\right)^{5}}}\right)+\frac{(\gamma+2) \beta^{2} \gamma^{2} \theta p^{2(\gamma-1)}}{4 \sqrt{\left(\alpha-\beta p^{\gamma}\right)^{5}}} .
$$

Next, we study separately two scenarios: when $\gamma \geq 1$ and when $0<\gamma<1$.

\subsection{Optimum Solution for the Case $\gamma \geq 1$}

In this scenario the function $f(p)$ is strictly convex. Thus, the optimum value of the unit selling price $p$ is determined by the following result.

Theorem 1. Let $B(p), f(p)$ and $f^{\prime}(p)$ be the functions given by (15), (18) and (19), respectively. When $\gamma \geq 1$, the optimal inventory policy is as follows: 
1. If $f^{\prime}(c)$ is non-negative, then the optimum unit selling price is $p^{*}=p_{m}$ and the maximum profit per unit time is $B^{*}=B\left(p^{*}\right)=0$.

2. Otherwise $\left(f^{\prime}(c)<0\right)$, let $p_{1}=\arg _{p \in\left(c, p_{m}\right)}\left\{f^{\prime}(p)=0\right\}$.

(a) If $f\left(p_{1}\right) \geq 0$, then $p^{*}=p_{m}$ and $B^{*}=B\left(p_{m}\right)=0$.

(b) If $f\left(p_{1}\right)<0$, then to let $p_{0}=\arg _{p \in\left(c, p_{1}\right)}\{f(p)=0\}$.

i. If $B\left(p_{0}\right)<0$, then $p^{*}=p_{m}$ and $B^{*}=B\left(p^{*}\right)=0$.

ii. If $B\left(p_{0}\right) \geq 0$, then $p^{*}=p_{0}$ and the maximum profit per unit time is $B^{*}=$ $B\left(p_{0}\right)=\left(p_{0}-c\right)\left(\alpha-\beta p_{0}^{\gamma}\right)-2 \theta \sqrt{\alpha-\beta p_{0}^{\gamma}}$.

Proof. Please see the proof in the Appendix A.

Remark 1. From Theorem 1, the optimal selling price $p^{*}$ when $\gamma \geq 1$ is either $p_{m}$ or $p_{0}=\arg _{p \in\left(c, p_{1}\right)}\{f(p)=0\}$. This optimum price $p^{*}$ depends whether the values $f^{\prime}(c), f\left(p_{1}\right)$ and $B\left(p_{0}\right)$ are positive or not.

Taking into account Theorem 1, the following algorithmic procedure gives the optimal inventory policy when $\gamma \geq 1$.

\subsection{Optimum Solution for the Case $0<\gamma<1$}

Consider now the scenario where $0<\gamma<1$. In this case, the curvature of the function $f(p)$ is unknown. For that, we have to study the behavior of the derivative of the function $f(p)$.

Lemma 1. The function $f^{\prime}(p)$ given by (19) is strictly convex.

Proof. Please see the Appendix A.

Note that if $0<\gamma<1$, then the function $f^{\prime}(p)$ has at most two zeros. Therefore, the function $f(p)$ has at most two local extreme points in the interval $\left(c, p_{m}\right)$. Taking into account this property, the optimal inventory policy when $0<\gamma<1$ is presented in the following result.

Theorem 2. Let $B(p), f(p), f^{\prime}(p)$ and $f^{\prime \prime}(p)$ be the functions given by (15), (18)-(20), respectively. Suppose that $0<\gamma<1$. The optimal inventory policy is as follows:

1. If $f^{\prime}(c) \geq 0$ and $f^{\prime \prime}(c) \geq 0$, then the optimum unit selling price is $p^{*}=p_{m}$ and the maximum profit is $B^{*}=B\left(p_{m}\right)=0$.

2. If $f^{\prime}(c) \geq 0$ and $f^{\prime \prime}(c)<0$, then to let $p_{2}=\arg _{p \in\left(c, p_{m}\right)}\left\{f^{\prime \prime}(p)=0\right\}$.

(a) If $f^{\prime}\left(p_{2}\right) \geq 0$, then $p^{*}=p_{m}$ and $B^{*}=B\left(p_{m}\right)=0$.

(b) If $f^{\prime}\left(p_{2}\right)<0$, then to let $p_{3}=\arg _{p \in\left(c, p_{2}\right)}\left\{f^{\prime}(p)=0\right\}$ and $p_{4}=\arg _{p \in\left(p_{2}, p_{m}\right)}\left\{f^{\prime}(p)=0\right\}$.

i. If $f\left(p_{4}\right) \geq 0$, then $p^{*}=p_{m}$ and $B^{*}=B\left(p_{m}\right)=0$.

ii. If $f\left(p_{4}\right)<0$, then to let $p_{5}=\arg _{p \in\left(p_{3}, p_{4}\right)}\{f(p)=0\}$.

(A) If $B\left(p_{5}\right)<0$, then $p^{*}=p_{m}$ and $B^{*}=B\left(p_{m}\right)=0$.

(B) If $B\left(p_{5}\right) \geq 0$, then $p^{*}=p_{5}$ and the maximum profit is given by $B^{*}=$ $\left.B\left(p_{5}\right)=p_{5}-c\right)\left(\alpha-\beta p_{5}^{\gamma}\right)-2 \theta \sqrt{\alpha-\beta p_{5}^{\gamma}}$.

3. If $f^{\prime}(c)<0$, then to let $p_{1}=\arg _{p \in\left(c, p_{m}\right)}\left\{f^{\prime}(p)=0\right\}$.

(a) If $f\left(p_{1}\right) \geq 0$, then $p^{*}=p_{m}$ and $B^{*}=B\left(p_{m}\right)=0$.

(b) If $f\left(p_{1}\right)<0$, let $p_{0}=\arg _{p \in\left(c, p_{1}\right)}\{f(p)=0\}$.

i. If $B\left(p_{0}\right)<0$, then $p^{*}=p_{m}$ and $B^{*}=B\left(p_{m}\right)=0$. 
ii. If $B\left(p_{0}\right) \geq 0$, then $p^{*}=p_{0}$ and the maximum profit is $B^{*}=B\left(p_{0}\right)=\left(p_{0}-\right.$ c) $\left(\alpha-\beta p_{0}^{\gamma}\right)-2 \theta \sqrt{\alpha-\beta p_{0}^{\gamma}}$.

Proof. Please see Appendix A.

Remark 2. From Theorem 2, the optimal selling price $p^{*}$ when $0<\gamma<1$ is $p_{m}$, $p_{0}=\arg _{p \in\left(c, p_{1}\right)}\{f(p)=0\}$, or $p_{5}=\arg _{p \in\left(p_{3}, p_{4}\right)}\{f(p)=0\}$. This optimum price $p^{*}$ is conditioned by the sign of the values $f^{\prime}(c), f^{\prime \prime}(c), f\left(p_{1}\right), f\left(p_{4}\right), f^{\prime}\left(p_{2}\right), B\left(p_{0}\right)$ and $B\left(p_{5}\right)$.

The following algorithmic approach determines the optimum inventory policy when $0<\gamma<1$.

Remark 3. Note that if $p^{*}=p_{m}$, then the inventory system is unprofitable.

\subsection{Particular Models}

In this subsection, we comment that some models studied by other authors are specific cases from the model proposed in this paper.

(1) If we consider $\beta \rightarrow 0$, then we have the inventory model with power demand pattern and full backlogging analyzed by Sicilia et al. [16].

(2) If we assume that $n=1$ and $\beta \rightarrow 0$, then the inventory problem is reduced to $\max _{0 \leq b \leq Q} G_{0}(Q, b)=(p-c) \alpha-A \frac{\alpha}{Q}-h \frac{(Q-b)^{2}}{2 Q}-\pi \frac{b^{2}}{2 Q}$, where $b=-s$, that is, we derive to the EOQ model with full backordeing (see, e.g., Axsäter [33], p. 31).

(3) Considering that $n=1, \gamma=1$ and $\pi \rightarrow \infty$, we derive using the models developed by Smith et al. [22], and Kunreuther and Richard [34] when a linear demand is assumed. Besides, the optimal policy determined by Algorithm 1 is equal to the "simultaneous solution" proposed by the cited authors.

(4) Also, when $n=1, \gamma=1$ and $\pi \rightarrow \infty$, we obtain the model studied by Kabirian [35] if we suppose that the demand rate is constant, the production cost is fixed and the production rate is infinite.

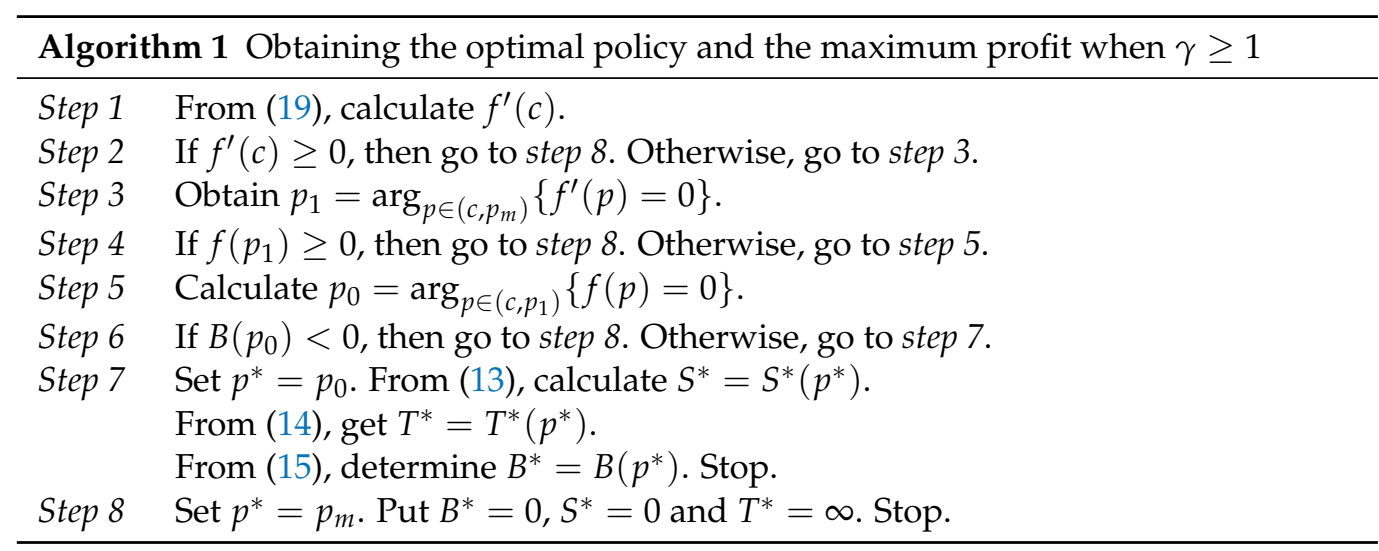

\section{Numerical Examples}

In this section, several numerical examples are presented to illustrate the theoretical results previously developed.

Example 1. Suppose an inventory system for a single item with the same properties as those described in Section 2. Consider the following parameters: purchasing cost $c=\$ 8$ per unit, ordering cost $A=\$ 500$ per order, unit holding cost $h=\$ 2$ per unit and month, shortage $\operatorname{cost} \pi=\$ 3.2$ per unit and month, and the index of the power demand pattern $n=2.5$. In addition, the demand rate per month is a function dependent on $p$ which is fitted to the expression 
$D_{2}(p)=\alpha-\beta p^{\gamma}$, with the parameters $\alpha=1280, \beta=40$ and $\gamma=1.25$. Firstly, the maximum unit selling price $p_{m}=\$ 16$ per unit has to be calculated. Applying step 1 of Algorithm 1, we have $f^{\prime}(c)=-2.80766<0$. Next, the point $p_{1}=\arg _{p \in(8,16)}\left\{f^{\prime}(p)=0\right\}=15.5006$ is calculated. Also, $f\left(p_{1}\right)=-6.23179<0$ and, from step 5 , we have $p_{0}=\arg _{p \in\left(8, p_{1}\right)}\{f(p)=0\}=12.4417$. As $B\left(p_{0}\right)=1005.97>0$, it is deduced that the optimum unit selling price is $p^{*}=p_{0}=\$ 12.4417$ per unit and the maximum profit is $B^{*}=B\left(p_{0}\right)=\$ 1005.97$ per month. From (13), the maximum inventory level is $S^{*}=538.721$ units and, from (14), the optimum inventory cycle is $T^{*}=1.89441$ months. Therefore, the economic lot size is $Q^{*}=654.192$ units. Figure 4 shows the functions $f(p)$ and $B(p)$ of this numerical example.
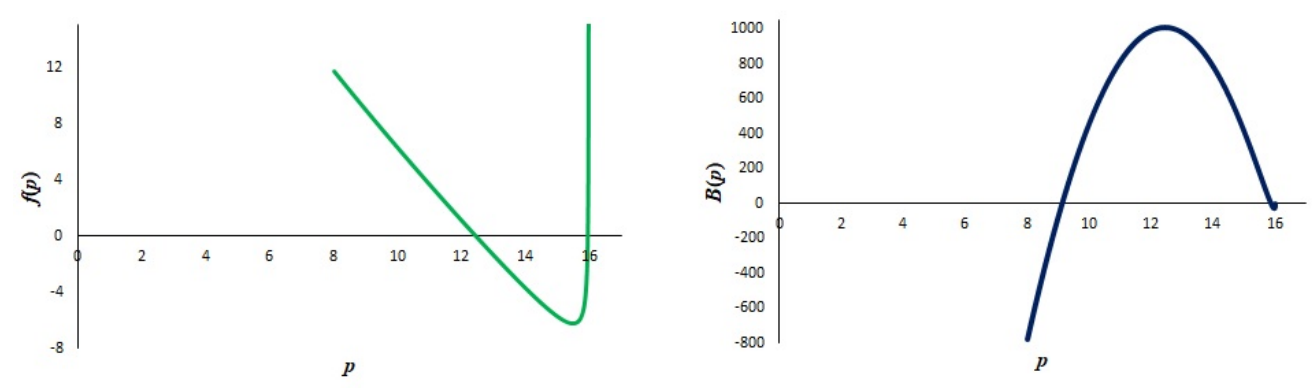

Figure 4. Functions $f(p)$ and $B(p)$ for Example 1 .

Example 2. Assume the same parameters as in Example 1, but now the values of $c$ and $\alpha$ are changed to $c=\$ 6.25$ per unit and $\alpha=640$, respectively. Then the maximum unit selling price is $p_{m}=\$ 9.18959$ per unit. From step 1 of Algorithm $1, f^{\prime}(c)=-2.47145$. From step 3 , it follows that $p_{1}=8.66838$. As $f\left(p_{1}\right)=0.278539>0$, it can be concluded that, for any unit selling price, the inventory system cannot be profitable.

Example 3. Assume the same parameters as Example 1, except for the values of $\beta$ and $\gamma$. Now, assume that these parameters are $\beta=80$ and $\gamma=0.8$. The value of $p_{m}$ is now $p_{m}=\$ 32$ per unit. As $0<\gamma<1$, then the steps of Algorithm 2 are followed to find the optimal inventory policy. Thus, we have $f^{\prime}(c)=-1.18416<0, p_{1}=\arg _{p \in(8,32)}\left\{f^{\prime}(p)=0\right\}=31.2652, f\left(p_{1}\right)=15.6852$, $p_{0}=\arg _{p \in\left(8, p_{1}\right)}\{f(p)=0\}=20.0649$ and $B\left(p_{0}\right)=4245.02$. Consequently, the optimum unit selling price is $p^{*}=p_{0}=\$ 20.0649$ per unit, the inventory level is $S^{*}=578.982$ units, the inventory cycle is $T^{*}=1.76268$ months, the economic lot size is $Q^{*}=703.082$ units and the maximum profit per unit time is $B^{*}=\$ 4245.02$ per month. The functions $f(p)$ and $B(p)$ are shown in Figure 5.
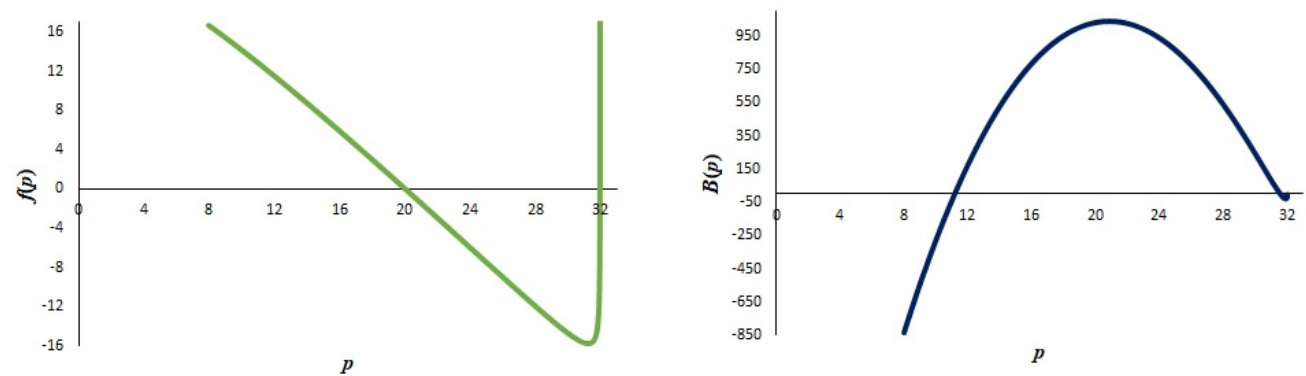

Figure 5. Functions $f(p)$ and $B(p)$ for Example 3. 


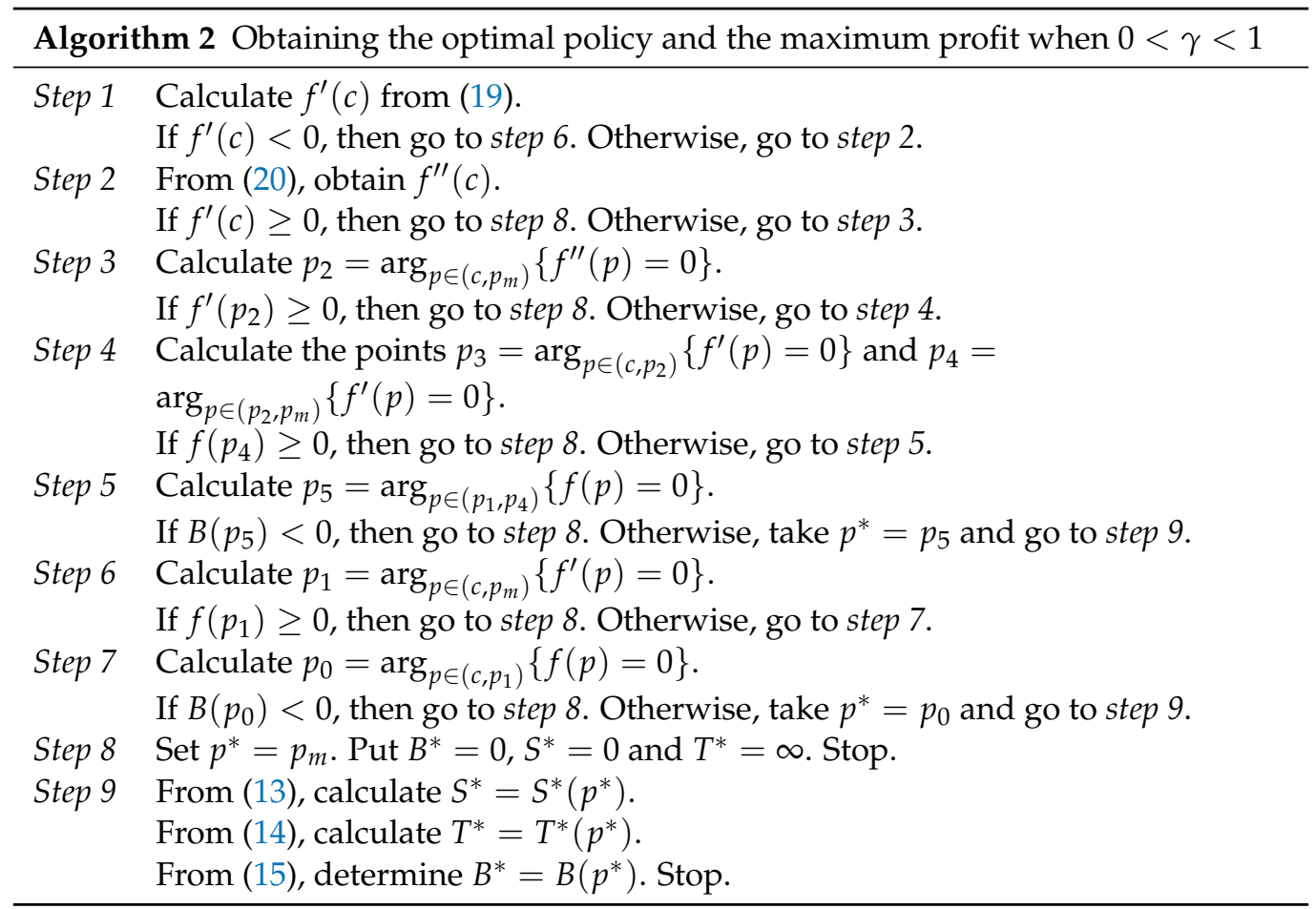

Example 4. Consider the same parameters as in Example 3, but changing the unit purchasing cost to $c=\$ 2$ per unit. Following Algorithm 2, we have $f^{\prime}(c)=0.0461332, f^{\prime \prime}(c)=-0.735387$, $p_{2}=24.0160, f^{\prime}(p 2)=-1.50313, p_{3}=2.06455, p_{4}=31.2652, f\left(p_{4}\right)=-20.4852, p_{5}=$ 16.7939 and $B\left(p_{5}\right)=6985.45$. Therefore, the optimal unit selling price is $p^{*}=p_{5}=\$ 16.7939$ per unit, the inventory level is $S^{*}=658.394$ units, the inventory cycle is $T^{*}=1.55008$ months, the economic lot size is $Q^{*}=799.517$ units and the profit per unit time is $B^{*}=\$ 6985.45$ per month. The functions $f(p)$ and $B(p)$ are plotted in Figure 6.
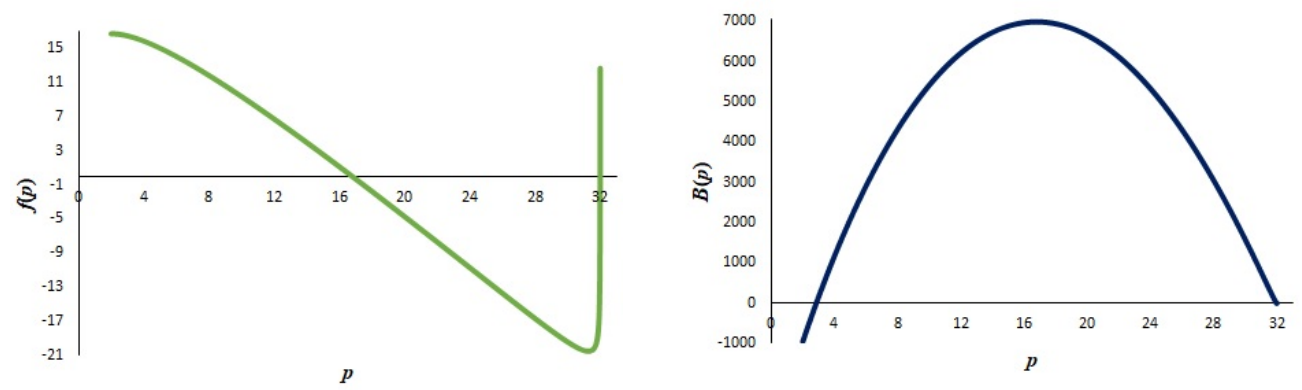

Figure 6. Functions $f(p)$ and $B(p)$ for Example 4 .

\section{Sensitivity Analysis}

To analyze the effect of the parameters of the demand rate $\alpha, \beta, \gamma$ and $n$ on the optimal policy and the maximum profit, three tables are presented where the evolution of the optimal policy $p^{*}, T^{*}, S^{*}$ and the maximum profit $B^{*}$ is shown for different values of $\alpha, \beta, \gamma$ and $n$. We assume the parameters $c=8, A=500, h=2$ and $\pi=3.2$. Tables 2-4 display computational results where $\alpha \in\{960,1280,1600\}, \beta \in\{36,40,44,48\}$, $\gamma \in\{0.8,0.9,1,1.1,1.2\}$ and $n \in\{0.5,1,2\}$. The obtained results can help us to identify some insights into the model presented in this paper. These characteristics are noted below:

1. When $\beta, \gamma$ and $n$ are fixed, the optimal selling price $p^{*}$, the optimal maximum inventory level $S^{*}$ and the maximum profit per unit time $B^{*}$ increase as the parameter $\alpha$ increases. However, the optimal inventory cycle $T^{*}$ decreases as $\alpha$ increases. 
2. With fixed $\alpha, \gamma$ and $n$, if the value of $\beta$ is increasing, then there is a point $\widehat{\beta}$ such that $p^{*}(\beta)<p_{m}$ and $B\left(p^{*}(\beta)\right)>0$ for all $\beta<\widehat{\beta}$, and $p^{*}(\beta)=p_{m}$ and $B\left(p^{*}(\beta)\right)=0$ if $\beta \geq \widehat{\beta}$. Moreover, when $\beta<\widehat{\beta}$, the optimal unit selling price, the maximum inventory level and the optimal profit are all strictly decreasing as the parameter $\beta$ increases, while the optimal inventory cycle is strictly decreasing as the parameter $\beta$ increases.

3. With fixed $\alpha, \beta$ and $n$, if the value of $\gamma$ is increasing, then there is a point $\widehat{\gamma}$ such that $p^{*}(\gamma)<p_{m}$ and $B\left(p^{*}(\gamma)\right)>0$ for all $\gamma<\widehat{\gamma}$, and $p^{*}(\gamma)=p_{m}$ and $B\left(p^{*}(\gamma)\right)=0$ if $\gamma \geq \widehat{\gamma}$. Moreover, when $\gamma<\widehat{\gamma}$, the optimal unit selling price, the maximum inventory level and the optimal profit are all strictly decreasing as the parameter $\gamma$ increases. However, the optimal inventory cycle is strictly decreasing as the parameter $\gamma$ increases.

4. With fixed $\alpha, \beta$ and $\gamma$, if the index of the power demand pattern $n$ is increasing, then there is a point $\widehat{n}$ such that $p^{*}(n)<p_{m}$ and $B\left(p^{*}(n)\right)>0$ for all $n>\widehat{n}$, and $p^{*}(n)=p_{m}$ and $B\left(p^{*}(n)\right)=0$ if $n<\widehat{n}$. Moreover, when $n>\widehat{n}$, the optimal unit selling price, the maximum inventory level and the optimal profit are all strictly decreasing as the parameter $n$ increases. However, the optimal inventory cycle is strictly decreasing as the parameter $n$ increases.

5. The optimal inventory policy and the maximum unit selling price are not very sensitive to changes in the demand pattern index $n$. However, the optimal solution is quite sensitive to changes in the value of $\gamma$.

Next, we present some findings obtained from the sensitivity analysis. Thus, the modification of the parameter $\alpha$ associated with the price-dependent demand has a greater effect on the total profit per unit time in a positive way, more so than the variation of the sensibility parameter $\beta$ for the price-dependent demand. Therefore, the decision maker should boost the price-dependent demand by implementing policies that increase the parameter $\alpha$ of the demand rate (for example, applying some marketing policies such as quantity discount).

Table 2. Sensitivity of the optimal policy $\left(p^{*}, T^{*}, S^{*}\right)$ and the maximum profit $B^{*}$ to variations of the parameters $\alpha, \beta$ and $\gamma$ when $n=0.5$.

\begin{tabular}{|c|c|c|c|c|c|c|c|c|c|c|c|c|c|}
\hline \multirow{2}{*}{$\gamma$} & \multirow{2}{*}{$\beta$} & \multicolumn{4}{|c|}{$\alpha=960$} & \multicolumn{4}{|c|}{$\alpha=1280$} & \multicolumn{4}{|c|}{$\alpha=1600$} \\
\hline & & $p^{*}$ & $T^{*}$ & $S^{*}$ & $B^{*}$ & $p^{*}$ & $T^{*}$ & $S^{*}$ & $B^{*}$ & $p^{*}$ & $T^{*}$ & $S^{*}$ & $B^{*}$ \\
\hline \multirow{5}{*}{0.8} & 36 & 33.9703 & 1.45619 & 196.207 & 8553.46 & 46.4856 & 1.22414 & 233.400 & $18,559.5$ & 59.8418 & 1.07770 & 265.116 & $32,748.6$ \\
\hline & 40 & 30.3818 & 1.47661 & 193.493 & 7067.43 & 41.3443 & 1.23530 & 231.291 & $15,676.4$ & 53.0474 & 1.08485 & 263.368 & $27,956.3$ \\
\hline & 44 & 27.5188 & 1.49838 & 190.682 & 5891.73 & 37.2418 & 1.24702 & 229.117 & $13,385.2$ & 47.6258 & 1.09231 & 261.568 & $24,141.2$ \\
\hline & 48 & 25.1870 & 1.52160 & 187.772 & 4943.42 & 33.8999 & 1.25932 & 226.879 & $11,527.4$ & 43.2094 & 1.10008 & 259.720 & $21,041.5$ \\
\hline & 36 & 23.5002 & 1.48305 & 192.653 & 4642.68 & 30.5146 & 1.22897 & 232.483 & $10,432.9$ & 37.7596 & 1.07359 & 266.129 & $18,548.4$ \\
\hline \multirow{3}{*}{0.9} & 40 & 21.4261 & 1.51393 & 188.724 & 3759.01 & 27.6536 & 1.24552 & 229.393 & 8755.38 & 34.0919 & 1.08421 & 263.524 & $15,824.0$ \\
\hline & 44 & 19.7499 & 1.54726 & 184.659 & 3056.64 & 25.3395 & 1.26295 & 226.227 & 7409.87 & 31.1246 & 1.09525 & 260.866 & $13,631.0$ \\
\hline & 48 & 18.3692 & 1.58335 & 180.449 & 2488.97 & 23.4312 & 1.28132 & 222.984 & 6310.84 & 28.6771 & 1.10676 & 258.155 & $11,832.2$ \\
\hline \multirow{4}{*}{1.0} & 36 & 17.8440 & 1.54124 & 185.380 & 2477.78 & 22.1928 & 1.25233 & 228.146 & 6029.07 & 26.5811 & 1.08315 & 263.782 & $11,025.9$ \\
\hline & 40 & 16.5264 & 1.58864 & 179.849 & 1919.45 & 20.4230 & 1.27641 & 223.842 & 4969.40 & 24.3639 & 1.09831 & 260.140 & 9324.21 \\
\hline & 44 & 15.4530 & 1.64129 & 174.079 & 1478.07 & 18.9769 & 1.30206 & 219.432 & 4116.89 & 22.5510 & 1.11418 & 256.435 & 7945.94 \\
\hline & 48 & 14.5634 & 1.70034 & 168.033 & 1124.65 & 17.7739 & 1.32947 & 214.908 & 3419.84 & 21.0414 & 1.13081 & 252.664 & 6810.27 \\
\hline \multirow{4}{*}{1.1} & 36 & 14.4814 & 1.64466 & 173.722 & 1199.80 & 17.3675 & 1.29742 & 220.218 & 3427.85 & 20.2414 & 1.10705 & 258.087 & 6632.63 \\
\hline & 40 & 13.5922 & 1.72277 & 165.846 & 841.104 & 16.1880 & 1.33301 & 214.337 & 2726.39 & 18.7877 & 1.12860 & 253.159 & 5503.76 \\
\hline & 44 & 12.8678 & 1.81504 & 157.415 & 563.855 & 15.2179 & 1.37185 & 208.269 & 2164.65 & 17.5896 & 1.15144 & 248.137 & 4588.56 \\
\hline & 48 & 12.2713 & 1.92721 & 148.253 & 348.750 & 14.4066 & 1.41454 & 201.984 & 1708.73 & 16.5850 & 1.17573 & 243.010 & 3835.05 \\
\hline \multirow{4}{*}{1.2} & 36 & 12.3573 & 1.83341 & 155.837 & 432.572 & 14.3471 & 1.37315 & 208.072 & 1811.40 & 16.3340 & 1.14852 & 248.767 & 3895.96 \\
\hline & 40 & 11.7473 & 1.98802 & 143.718 & 212.329 & 13.5204 & 1.42881 & 199.967 & 1340.28 & 15.3235 & 1.17984 & 242.164 & 3121.70 \\
\hline & 44 & 11.2706 & 2.20618 & 129.506 & 53.7066 & 12.8395 & 1.49242 & 191.444 & 969.265 & 14.4864 & 1.21383 & 235.382 & 2497.59 \\
\hline & 48 & 12.1392 & $\infty$ & 0 & 0 & 12.2711 & 1.56645 & 182.396 & 674.862 & 13.7818 & 1.25100 & 228.389 & 1987.96 \\
\hline
\end{tabular}


Table 3. Sensitivity of the optimal policy $\left(p^{*}, T^{*}, S^{*}\right)$ and the maximum profit $B^{*}$ to variations of the parameters $\alpha, \beta$ and $\gamma$ when $n=1$.

\begin{tabular}{|c|c|c|c|c|c|c|c|c|c|c|c|c|c|}
\hline \multirow{2}{*}{$\gamma$} & \multirow{2}{*}{$\beta$} & \multicolumn{4}{|c|}{$\alpha=960$} & \multicolumn{4}{|c|}{$\alpha=1280$} & \multicolumn{4}{|c|}{$\alpha=1600$} \\
\hline & & $p^{*}$ & $T^{*}$ & $S^{*}$ & $B^{*}$ & $p^{*}$ & $T^{*}$ & $S^{*}$ & $B^{*}$ & $p^{*}$ & $T^{*}$ & $S^{*}$ & $B^{*}$ \\
\hline \multirow{4}{*}{0.8} & 36 & 33.9511 & 1.51058 & 330.999 & 8578.45 & 46.4695 & 1.27008 & 393.676 & $18,589.2$ & 59.8275 & 1.11822 & 447.139 & $32,782.3$ \\
\hline & 40 & 30.3624 & 1.53166 & 326.444 & 7092.07 & 41.3280 & 1.28161 & 390.134 & $15,705.9$ & 53.0330 & 1.12562 & 444.200 & $27,989.8$ \\
\hline & 44 & 27.4991 & 1.55412 & 321.725 & 5916.01 & 37.2254 & 1.29372 & 386.481 & $13,414.4$ & 47.6114 & 1.13334 & 441.175 & $24,174.5$ \\
\hline & 48 & 25.1671 & 1.57807 & 316.843 & 4967.34 & 33.8833 & 1.30643 & 382.722 & $11,556.3$ & 43.1949 & 1.14137 & 438.070 & $21,074.6$ \\
\hline \multirow{4}{*}{0.9} & 36 & 23.4815 & 1.53804 & 325.089 & 4667.22 & 30.4991 & 1.27491 & 392.186 & 1.04625 & 37.7460 & 1.11386 & 448.889 & $18,582.3$ \\
\hline & 40 & 21.4069 & 1.56987 & 318.498 & 3783.04 & 27.6379 & 1.29200 & 386.997 & 8784.59 & 34.0782 & 1.12483 & 444.511 & $15,857.6$ \\
\hline & 44 & 19.7302 & 1.60420 & 311.683 & 3080.16 & 25.3236 & 1.31000 & 381.681 & 7438.68 & 31.1108 & 1.13625 & 440.044 & $13,664.2$ \\
\hline & 48 & 18.3491 & 1.64135 & 304.628 & 2511.96 & 23.4151 & 1.32895 & 376.237 & 6339.24 & 28.6632 & 1.14813 & 435.490 & $11,865.1$ \\
\hline \multirow{5}{*}{1.0} & 36 & 17.8249 & 1.59769 & 312.952 & 2501.40 & 22.1774 & 1.29886 & 384.953 & 6058.12 & 26.5680 & 1.12362 & 444.990 & $11,059.5$ \\
\hline & 40 & 16.5066 & 1.64643 & 303.688 & 1942.36 & 20.4073 & 1.32370 & 377.729 & 4997.91 & 24.3505 & 1.13929 & 438.872 & 9357.34 \\
\hline & 44 & 15.4323 & 1.70050 & 294.032 & 1500.25 & 18.9609 & 1.35014 & 370.331 & 4144.84 & 22.5374 & 1.15567 & 432.650 & 7978.59 \\
\hline & 48 & 14.5419 & 1.76104 & 283.924 & 1146.06 & 17.7575 & 1.37839 & 362.743 & 3447.21 & 21.0275 & 1.17283 & 426.318 & 6842.45 \\
\hline & 36 & 14.4610 & 1.70352 & 293.510 & 1221.94 & 17.3519 & 1.34516 & 371.704 & 3455.90 & 20.2282 & 1.14818 & 435.472 & 6665.50 \\
\hline \multirow{3}{*}{1.1} & 40 & 13.5704 & 1.78345 & 280.356 & 862.244 & 16.1719 & 1.38180 & 361.846 & 2753.69 & 18.7742 & 1.17041 & 427.199 & 5536.00 \\
\hline & 44 & 12.8444 & 1.87758 & 266.300 & 583.928 & 15.2011 & 1.42175 & 351.680 & 2191.18 & 17.5757 & 1.19397 & 418.772 & 4620.16 \\
\hline & 48 & 12.2457 & 1.99149 & 251.069 & 367.666 & 14.3892 & 1.46560 & 341.157 & 1734.46 & 16.5708 & 1.21901 & 410.170 & 3866.00 \\
\hline \multirow{4}{*}{1.2} & 36 & 12.3337 & 1.89549 & 263.783 & 452.449 & 14.3305 & 1.42282 & 351.415 & 1837.91 & 16.3204 & 1.19081 & 419.881 & 3927.65 \\
\hline & 40 & 11.7204 & 2.05175 & 243.694 & 230.677 & 13.5029 & 1.47992 & 337.857 & 1365.76 & 15.3094 & 1.22307 & 408.809 & 3152.54 \\
\hline & 44 & 11.2384 & 2.26931 & 220.331 & 70.2684 & 12.8210 & 1.54503 & 323.618 & 993.668 & 14.4718 & 1.25804 & 397.443 & 2527.57 \\
\hline & 48 & 12.1392 & $\infty$ & 0 & 0 & 12.2512 & 1.62061 & 308.526 & 698.120 & 13.7666 & 1.29624 & 385.731 & 2017.06 \\
\hline
\end{tabular}

Table 4. Sensitivity of the optimal policy $\left(p^{*}, T^{*}, S^{*}\right)$ and the maximum profit $B^{*}$ to variations of the parameters $\alpha, \beta$ and $\gamma$ when $n=2$.

\begin{tabular}{|c|c|c|c|c|c|c|c|c|c|c|c|c|c|}
\hline \multirow{2}{*}{$\gamma$} & \multirow{2}{*}{$\beta$} & \multicolumn{4}{|c|}{$\alpha=960$} & \multicolumn{4}{|c|}{$\alpha=1280$} & \multicolumn{4}{|c|}{$\alpha=1600$} \\
\hline & & $p^{*}$ & $T^{*}$ & $S^{*}$ & $B^{*}$ & $p^{*}$ & $T^{*}$ & $S^{*}$ & $B^{*}$ & $p^{*}$ & $T^{*}$ & $S^{*}$ & $B^{*}$ \\
\hline \multirow{4}{*}{0.8} & 36 & 33.8825 & 1.74515 & 488.802 & 8668.27 & 46.4115 & 1.46819 & 581.010 & $18,696.0$ & 59.7763 & 1.29299 & 659.737 & $32,903.6$ \\
\hline & 40 & 30.2930 & 1.76906 & 482.195 & 7180.67 & 41.2697 & 1.48133 & 575.856 & $15,811.7$ & 52.9816 & 1.30144 & 655.453 & $28,110.4$ \\
\hline & 44 & 27.4287 & 1.79451 & 475.356 & 6003.34 & 37.1665 & 1.49512 & 570.543 & $13,519.2$ & 47.5597 & 1.31025 & 651.045 & $24,294.2$ \\
\hline & 48 & 25.0957 & 1.82161 & 468.285 & 5053.36 & 33.8240 & 1.50959 & 565.078 & $11,660.1$ & 43.1429 & 1.31942 & 646.519 & $21,193.5$ \\
\hline \multirow{4}{*}{0.9} & 36 & 23.4143 & 1.77522 & 480.524 & 4755.49 & 30.4435 & 1.47302 & 579.107 & $10,568.9$ & 37.6974 & 1.28752 & 662.542 & $18,704.1$ \\
\hline & 40 & 21.3383 & 1.81114 & 470.992 & 3869.54 & 27.5816 & 1.49245 & 571.567 & 8889.63 & 34.0292 & 1.30003 & 656.165 & $15,978.2$ \\
\hline & 44 & 19.6600 & 1.84981 & 461.147 & 3164.82 & 25.2664 & 1.51288 & 563.848 & 7542.28 & 31.0613 & 1.31304 & 649.662 & $13,783.6$ \\
\hline & 48 & 18.2771 & 1.89155 & 450.971 & 2594.73 & 23.3571 & 1.53438 & 555.946 & 6441.37 & 28.6132 & 1.32658 & 643.032 & $11,983.3$ \\
\hline \multirow{5}{*}{1.0} & 36 & 17.7566 & 1.84122 & 463.298 & 2586.43 & 22.1225 & 1.49954 & 568.863 & 6162.63 & 26.5207 & 1.29817 & 657.106 & $11,180.3$ \\
\hline & 40 & 16.4358 & 1.89577 & 449.966 & 2024.91 & 20.3512 & 1.52766 & 558.393 & 5100.47 & 24.3026 & 1.31599 & 648.208 & 9476.45 \\
\hline & 44 & 15.3588 & 1.95602 & 436.106 & 1580.22 & 18.9035 & 1.55754 & 547.680 & 4245.41 & 22.4887 & 1.33461 & 639.164 & 8096.03 \\
\hline & 48 & 14.4651 & 2.02312 & 421.642 & 1223.33 & 17.6987 & 1.58939 & 536.706 & 3545.75 & 20.9780 & 1.35409 & 629.967 & 6958.18 \\
\hline & 36 & 14.3883 & 1.95765 & 435.743 & 1301.81 & 17.2950 & 1.55109 & 549.956 & 3556.87 & 20.1810 & 1.32558 & 643.515 & 6783.72 \\
\hline \multirow{3}{*}{1.1} & 40 & 13.4933 & 2.04565 & 416.998 & 938.604 & 16.1141 & 1.59230 & 535.725 & 2852.02 & 18.7259 & 1.35078 & 631.512 & 5651.99 \\
\hline & 44 & 12.7618 & 2.14820 & 397.092 & 656.553 & 15.1413 & 1.63706 & 521.078 & 2286.78 & 17.5263 & 1.37742 & 619.298 & 4733.89 \\
\hline & 48 & 12.1561 & 2.27045 & 375.711 & 436.260 & 14.3270 & 1.68599 & 505.954 & 1827.25 & 16.5201 & 1.40568 & 606.846 & 3977.42 \\
\hline \multirow{4}{*}{1.2} & 36 & 12.2503 & 2.16454 & 394.094 & 524.458 & 14.2714 & 1.63717 & 521.041 & 1933.48 & 16.2720 & 1.37324 & 621.182 & 4041.70 \\
\hline & 40 & 11.6267 & 2.32965 & 366.163 & 297.397 & 13.4407 & 1.70059 & 501.611 & 1457.70 & 15.2593 & 1.40955 & 605.179 & 3263.62 \\
\hline & 44 & 11.1283 & 2.55028 & 334.486 & 130.916 & 12.7551 & 1.77238 & 481.292 & 1081.81 & 14.4199 & 1.44880 & 588.784 & 2635.60 \\
\hline & 48 & 10.7404 & 2.87924 & 296.271 & 12.1444 & 12.1809 & 1.85491 & 459.878 & 782.244 & 13.7127 & 1.49151 & 571.927 & 2121.96 \\
\hline
\end{tabular}

\section{Conclusions}

We have studied an inventory model where demand depends on time and the unit selling price. Shortages are allowed and completely backlogged. The objective is to maximize the profit per unit time, assuming that the profit is the difference between 
revenue obtained from product sales and the total inventory cost. This cost is the sum of the ordering, purchasing, holding and backordering costs.

We introduce an approach to determine the optimal inventory policy, the optimal selling-price and the maximum profit per unit time in all possible cases. In order to illustrate the theoretical results and the methodology developed for obtaining the optimal solution of the inventory problem, we have presented some numerical examples where the optimal inventory policies are determined following the steps described in the proposed algorithms.

To analyze the effect on the optimal policy of changes in the parameters associated with the demand rate, we present several computational results that allow us to carry out a sensitivity analysis of the inventory policy.

Future research lines related to this paper could be the following: (i) to study the inventory system for perishable items, considering the properties established in this paper; (ii) to analyze the same system assuming stochastic demand; and (iii) to consider partial backordering in the assumptions of the inventory system.

Author Contributions: Conceptualization, L.A.S.-J., J.S., M.G.-d.-1.-R. and J.F.-A.; Methodology, L.A.S.-J., J.S., M.G.-d.-1.-R. and J.F.-A.; writing—review \& editing, L.A.S.-J., J.S., M.G.-d.-1.-R. and J.F.A. All authors have read and agreed to the published version of the manuscript.

Funding: This work is partially supported by the Spanish Ministry of Science, Innovation and Universities through the research project MTM2017-84150-P, which is co-financed by the European Community under the European Regional Development Fund (ERDF).

Institutional Review Board Statement: Not applicable.

Informed Consent Statement: Not applicable.

Data Availability Statement: Not applicable.

Conflicts of Interest: The authors declare no conflict of interest.

\section{Appendix A}

Proof of Theorem 1. Since $\gamma \geq 1$, from (20) it follows that the function $f(p)$ is strictly convex. Taking into account that $f(c)=\frac{\left(\alpha-\beta c^{\gamma}\right)}{\beta} c^{1-\gamma}+\frac{\gamma \theta}{\sqrt{\alpha-\beta c \gamma}}>0$ and $\lim _{p \rightarrow p_{m}^{-}} f(p)=\infty$, we consider the following cases:

1. If $f^{\prime}(c) \geq 0$, then $f(p)$ is a strictly increasing function and, therefore, positive on the interval $\left[c, p_{m}\right)$. In consequence, the function $B(p)$ is also strictly increasing. Thus, it attains its maximum value at $p^{*}=p_{m}$.

2. It $f^{\prime}(c)<0$, let $p_{1}$ be the point where the function $f(p)$ attains its minimum value, that is, $p_{1}=\arg _{p \in\left(c, p_{m}\right)}\left\{f^{\prime}(p)=0\right\}$ (this point is unique, because $f$ is strictly convex with $\lim _{p \rightarrow p_{m}^{-}} f^{\prime}(p)=\infty$ ). We have two possibilities:

(a) If $f\left(p_{1}\right) \geq 0$, then $f(p)>0$ on the set $\left[c, p_{1}\right) \cup\left(p_{1}, p_{m}\right)$ and, therefore, $B(p)$ is a strictly increasing function. Then it attains its maximum value at $p^{*}=p_{m}$.

(b) If $f\left(p_{1}\right)<0$, then $f(p)$ has two roots in the interval $\left[c, p_{m}\right): p_{0} \in\left(c, p_{1}\right)$ and $\widetilde{p} \in\left(p_{1}, p_{m}\right)$. So $f(p)>0$ on the set $\left[c, p_{0}\right) \cup\left(\widetilde{p}, p_{m}\right)$ and $f(p)<0$ on the interval $\left(p_{0}, \widetilde{p}\right)$. Thus, the function $B(p)$ is strictly increasing on the interval $\left[c, p_{0}\right)$, strictly decreasing on $\left(p_{0}, \widetilde{p}\right)$ and strictly increasing on $\left(\widetilde{p}, p_{m}\right)$. Therefore, $B(p)$ attains its maximum value at $p_{0}$ or at $p_{m}$. Finally, considering that $B\left(p_{m}\right)=0$, the conclusion of the theorem is obtained.

Proof of Lemma 1. The proof is immediate, because

$$
f^{\prime \prime \prime}(p)=\left(1-\gamma^{2}\right) \frac{\alpha \gamma}{\beta} p^{-(\gamma+2)}+\frac{\beta \gamma^{2} \theta p^{\gamma-3}}{8{\sqrt{\left(\alpha-\beta p^{\gamma}\right)^{7}}}^{7}} g\left(p^{\gamma}\right),
$$


where $g(x)$ is a positive parabolic function given by

$$
g(x)=\beta^{2}(\gamma+2)(\gamma+4) x^{2}+2 \alpha \beta(\gamma-1)(5 \gamma+8) x+4 \alpha^{2}(\gamma-1)(\gamma-2) .
$$

Proof of Theorem 2. Taking into account the result of Lemma 1, we have that $f^{\prime}(p)$ is a strictly convex function and $\lim _{p \rightarrow p_{m}^{-}} f^{\prime}(p)=\infty$. Next, we consider the following two situations depending on the value of $f^{\prime}(c)$ :

1. If $f^{\prime}(c) \geq 0$, then the following three cases can occur:

(a) If $f^{\prime \prime}(c) \geq 0$, then the function $f^{\prime}(p)$ is strictly increasing for $p \in\left(c, p_{m}\right)$ and, since $f^{\prime}(c) \geq 0$, it is positive on such an interval. Therefore, $f(p)$ is a strictly increasing and positive function. Hence, the function $B(p)$ is strictly increasing. Then, it attains its maximum value at $p^{*}=p_{m}$.

(b) If $f^{\prime \prime}(c)<0$, then the function $f^{\prime \prime}(p)$ has a root $p_{2}$ in the interval $\left(c, p_{m}\right)$, because $\lim _{p \rightarrow p_{m}^{-}} f^{\prime \prime}(p)=\infty$. We have two possibilities:

i. If $f^{\prime}\left(p_{2}\right) \geq 0$, then $f^{\prime}(p)>0$ on the set $\left(c, p_{2}\right) \cup\left(p_{2}, p_{m}\right)$. Thus, $f(p)$ is a positive and strictly increasing function. Hence, the function $B(p)$ is strictly increasing. Then it attains its maximum value at $p^{*}=p_{m}$.

ii. If $f^{\prime}\left(p_{2}\right)<0$, the function $f^{\prime}(p)$ has two zeros in the interval $\left(c, p_{m}\right): p_{3} \in$ $\left(c, p_{2}\right)$ and $p_{4} \in\left(p_{2}, p_{m}\right)$, so that $f^{\prime}(p)>0$ on the set $\left[c, p_{3}\right) \cup\left(p_{4}, p_{m}\right]$ and $f^{\prime}(p)<0$ on the interval $\left(p_{3}, p_{4}\right)$. That is, the function $f(p)$ is strictly increasing on $\left[c, p_{3}\right)$, strictly decreasing on $\left(p_{3}, p_{4}\right)$ and strictly increasing on $\left(p_{4}, p_{m}\right]$. Now, two cases can occur:

A. If $f\left(p_{4}\right) \geq 0$, then the function $f(p)$ is positive on the set $\left(c, p_{4}\right) \cup\left(p_{4}, p_{m}\right)$. Thus, the function $B(p)$ attains its maximum value at $p_{m}$.

B. If $f\left(p_{4}\right)<0$, then the function $f(p)$ has two roots in the interval $\left[c, p_{m}\right): p_{5} \in\left(p_{3}, p_{4}\right)$ and $\widetilde{p} \in\left(p_{4}, p_{m}\right)$. Besides, $f(p)>0$ on $\left[c, p_{5}\right) \cup\left(\widetilde{p}, p_{m}\right]$ and $f(p)<0$ on $\left(p_{5}, \widetilde{p}\right)$. Thus, $B(p)$ is strictly increasing on $\left[c, p_{5}\right)$, strictly decreasing on $\left(p_{5}, \widetilde{p}\right)$ and strictly increasing on $\left(\widetilde{p}, p_{m}\right]$. Therefore, its maximum value is attained at $p_{5}$ or at $p_{m}$. Since $B\left(p_{m}\right)=0$, the conclusion of the theorem is obtained.

2. If $f^{\prime}(c)<0$, then the function $f^{\prime}(p)$ has a unique zero, $p_{1}$, in the interval $\left(c, p_{m}\right)$, so that $f^{\prime}(p)<0$ on $\left(c, p_{1}\right)$ and $f^{\prime}(p)>0$ on $\left(p_{1}, p_{m}\right)$. Evaluating the function $f(p)$ at the point $p_{1}$, we have the following two possibilities:

(a) If $f\left(p_{1}\right) \geq 0$, then $f(p)$ is positive on $\left(c, p_{1}\right) \cup\left(p_{1}, p_{m}\right)$, because $f(c)>0$. Therefore, the function $B(p)$ attains its maximum value at $p^{*}=p_{m}$.

(b) If $f\left(p_{1}\right)<0$, then $f(p)$ has two roots in the interval $\left[c, p_{m}\right): p_{0} \in\left(c, p_{1}\right)$ and $\tilde{p} \in\left(p_{1}, p_{m}\right)$, such that $f(p)>0$ on the set $\left[c, p_{0}\right) \cup\left(\widetilde{p}, p_{m}\right)$ and $f(p)<0$ on the interval $\left(p_{0}, \widetilde{p}\right)$. The rest of the proof runs as in the case 1.b.ii.B.

\section{References}

1. Chung, K.J.; Lin, S.D.; Srivastava, H.M. The complete solution procedures for the mathematical analysis of some families of optimal inventory models with order-size dependent trade credit and deterministic and constant demand. Appl. Math. Comput. 2012, 219, 141-156. [CrossRef]

2. Vandana; Sharma, B.K. An EOQ model for retailers partial permissible delay in payment linked to order quantity with shortages. Math. Comput. Simul. 2016, 125, 99-112. [CrossRef]

3. Mokhtari, H. Economic order quantity for joint complementary and substitutable items. Math. Comput. Simul. 2018, 154, 34-47. [CrossRef]

4. Lin, F.; Jia, T.; Wu, F.; Yang, Z. Impacts of two-stage deterioration on an integrated inventory model under trade credit and variable capacity utilization. Eur. J. Oper. Res. 2019, 272, 219-234. [CrossRef] 
5. Chung, K.J.; Liao, J.J.; Lin, S.D.; Chuang, S.T.; Srivastava, H.M. The inventory model for deteriorating items under conditions involving cash discount and trade credit. Mathematics 2019, 7, 596. [CrossRef]

6. Khakzad, A.; Gholamian, M.R. The effect of inspection on deterioration rate: An inventory model for deteriorating items with advanced payment. J. Clean. Prod. 2020, 254, 120117. [CrossRef]

7. Mishra, U.; Wu, J.Z.; Sarkar, B. A sustainable production-inventory model for a controllable carbon emissions rate under shortages. J. Clean. Prod. 2020, 256, 120268. [CrossRef]

8. Naddor, E. Inventory Systems; John Wiley: New York, NY, USA, 1966.

9. Datta, T.K.; Pal, A.K. Order level inventory system with power demand pattern for items with variable rate of deterioration. Indian J. Pure Appl. MatH. 1988, 19, 1043-1053.

10. Lee, W.C.; Wu, J.W. An EOQ model for items with weibull distributed deterioration, shortages and power demand pattern. Int. J. Inform. Manag. Sci. 2002, 13, 19-34.

11. Rajeswari, N.; Vanjikkodi, T. Deteriorating inventory model with power demand and partial backlogging. Int. J. Math. Arch. 2011, 2, 1495-1501.

12. Mishra, S.; Raju, L.K.; Misra, U.K.; Misra, G. A study of EOQ model with power demand of deteriorating items under the influence of inflation. Gen. Math. Notes. 2012, 10, 41-50.

13. Singh, D.P.; Kumar, S. A study of order level inventory system using power demand pattern for deteriorate items. Int. J. Eng. Math. Sci. 2012, 1, 178-184.

14. Mishra, S.S.; Singh, P.K. Partial backlogging EOQ model for queued customers with power demand and quadratic deterioration: Computational approach. Am. J. Oper. Res. 2013, 3, 13-27.

15. Rajeswari, N.; Indrani, K. EOQ policies for linearly time dependent deteriorating items with power demand and partial backlogging. Int. J. Math. Arch. 2015, 6, 122-130.

16. Sicilia, J.; Febles-Acosta, J.; González-De la Rosa, M. Deterministic inventory systems with power demand pattern. Asia Pac. J. Oper. Res. 2012, 29, 1250025. [CrossRef]

17. Sicilia, J.; Febles-Acosta, J.; González-De la Rosa, M. Economic order quantity for a power demand pattern system with deteriorating items. Eur. J. Ind. Eng. 2013, 7, 577-593. [CrossRef]

18. San-José, L.A.; Sicilia, J.; González-De-la-Rosa, M.; Febles-Acosta, J. Optimal inventory policy under power demand pattern and partial backlogging. Appl. Math. Model. 2017, 4 ,618-630. [CrossRef]

19. Adaraniwon, A.O.; Omar, M.B. An inventory model for delayed deteriorating items with power demand considering shortages and lost sales. J. Intell. Fuzzy Syst. 2019, 36, 5397-5408. [CrossRef]

20. Adaraniwon, A.O.; Omar, M.B. An inventory model for linearly time-dependent deteriorating rate and time-varying demand with shortages partially backlogged. J. Intell. Fuzzy Syst. $2020,38,4545-4557$.

21. San-José, L.A.; Sicilia, J.; Abdul-Jalbar, B. Optimal policy for an inventory system with demand dependent on price, time and frequency of advertisement. Comput. Oper. Res. 2021, 128, 105169. [CrossRef]

22. Smith, N.R.; Martínez-Flores, J.L.; Cárdenas-Bar ón, L.E. Analysis of the benefits of joint price and order quantity optimisation using a deterministic profit maximisation model. Prod. Plan. Control. 2007, 18, 310-318. [CrossRef]

23. Soni, H.N. Optimal replenishment policies for non-instantaneous deteriorating items with price and stock sensitive demand under permissible delay in payment. Int. J. Prod. Econ. 2013, 146, 259-268. [CrossRef]

24. Wu, J.; Skouri, K.; Teng, J.T.; Ouyang, L.Y. A note on “Optimal replenishment policies for non-instantaneous deteriorating items with price and stock sensitive demand under permissible delay in payment". Int. J. Prod. Econ. 2014, 155, 324-329. [CrossRef]

25. Avinadav, T.; Herbon, A.; Spiegel, U. Optimal ordering and pricing policy for demand functions that are separable into price and inventory age. Int. J. Prod. Econ. 2014, 155, 406-417. [CrossRef]

26. San-José, L.A.; Sicilia, J.; González-De-la-Rosa, M.; Febles-Acosta, J. Best pricing and optimal policy for an inventory system under time-and-price-dependent demand and backordering. Ann. Oper. Res. 2020, 286, 351-369. [CrossRef]

27. Pando, V.; San-José, L.A.; Sicilia, J.; Alcaide-Ló pez-de-Pablo, D. Profitability index maximization in an inventory model with a price- and stock-dependent demand rate in a power-form. Mathematic 2021, 9, 1157. [CrossRef]

28. San-José, L.A.; García-Laguna, J. Optimal policy for an inventory system with backlogging and all-units discounts: Application to the composite lot size model. Eur. J. Oper. Res. 2009, 192, 808-823. [CrossRef]

29. Birbil, Ş.İ; Bülbül, K.; Frenk, J.B.G.; Mulder, H.M. On EOQ cost models with arbitrary purchase and transportation costs. J. Ind. Manag. Optim. 2015, 11, 1211-1245.

30. Jakšič, M.; Fransoo, J.C. Optimal inventory management with supply backordering. Int. J. Prod. Econ. 2015, 159, 254-264. [CrossRef]

31. Mishra, S.S.; Gupta, S.; Yadav, S.K.; Rawat, S. Optimization of fuzzified Economic Order Quantity model allowing shortage and deterioration with full backlogging. Am. J. Oper. Res. 2015, 5, 103-110.

32. San-José, L.A.; Sicilia, J.; González-De-la-Rosa, M.; Febles-Acosta, J. Analysis of an inventory system with discrete scheduling period, time-dependent demand and backlogged shortages. Comput. Oper. Res. 2019, 109, 200-208. [CrossRef]

33. Axsäter, S. Inventory Control; Springer: New York, NY, USA, 2000. 
34. Kunreuther, H.; Richard, J.F. Optimal pricing and inventory decisions for non-seasonal items. Econometrica 1971, $39,173-175$. [CrossRef]

35. Kabirian, A. The economic production and pricing model with lot-size-dependent production cost. J. Glob. Optim. 2012, 54, 1-15. [CrossRef] 